\title{
A HIPOTERMIA COMO ESTRATÉGIA PROTETORA DE ENCEFALOPATIA HIPÓXICO-ISQUÊMICA EM RECÉM-NASCIDOS COM ASFIXIA PERINATAL
}

\section{HYPOTHERMY AS A PROTECTIVE STRATEGY IN ASPHYXIATED NEWBORNS AFTER HYPOXIC-ISCHEMIC ENCEPHALOPATHY}

\author{
Adriana Silva de Araujo * \\ Sídia Serotti Pacheco * \\ Adriana Gonçalves de Oliveira *** \\ Caio Imaizumi * \\ Luiz Carlos de Abreu*
}

\section{RESUMO}

Introdução: a encefalopatia hipóxico isquêmica neonatal é uma doença devastadora para o cérebro do recém-nascido. Nas últimas duas décadas, as pesquisas experimentais trouxeram grande avanço nos conhecimentos fisiopatológicos. Para a integridade neuronal, é necessária energia suficiente para a célula manter o equilíbrio iônico. A hipotermia tem sido estudada como um método com alto grau de neuroproteção na hipóxia-isquemia (HI). Objetivo: verificar a potencialidade terapêutica da hipotermia como tratamento da encefalopatia hipóxico-isquêmica em recém-nascidos. Método: foram consultadas as bases de dados do Medline, Lilacs, Scielo e JCR-ISI. As consultas incluíram artigos registrados entre 1993 e 2008 no idioma Português, Inglês e Espanhol. Discussão: encefalopatia hipóxico- isquêmica neonatal é complicação imediata à asfixia grave e pode causar graus variados de dano cerebral. As características do dano hipóxico isquêmico indicam que existe um período intermediário, em que é possível intervir interrompendo a cadeia de eventos que levam a destruição celular definitiva. Com a finalidade de proteger o cérebro dos insultos isquêmicos, utilizam-se drogas e diferentes procedimentos, tais como manitol, removedores de radicais livres, antagonistas de receptores opiáceos, supressores de metabolismo e hipotermia para minimizar as lesões. Conclusão: o resfriamento cerebral é a conduta terapêutica promissora em reduzir danos cerebrais em recém-nascidos.

Palavras-chave: Recém-nascido; hipotermia; paralisia cerebral; fisiopatologia e encefalopatia.

\footnotetext{
* Especialização em Fisiologia. Faculdade de Medicina do ABC.

** Serviço de Neonatologia. Hospital Maternidade Leonor Mendes de Barros.

Correspondência para Luiz Carlos de Abreu. Faculdade de Medicina do ABC. Avenida Príncipe de Gales, 821. Santo André, SP. E-mail: abreu.luizcarlos@gmail.com
} 


\begin{abstract}
Introduction: The nutritional needs and particularly, the energetic metabolism in childhood is a controversy in the literature. Objective: To characterize the energetic spent at rest in children with sepsis. Method: The database of Medline and SciELO was consulted. We used as search strategy the words: newborn and energy spent or sepsis in all fields. Results: In the case of sepsis , the child presents immaturity of the enzymatic system, which limits the production of some aminoacids, such as cystein (cistationase enzyme deficit in preterm), taurine, gutamine and nucleotides as coline e inositol. This fact turns those nutrients conditionally essential for children. Conclusion: Many concepts for adults are used in childohood, which is not correct and may cause several consequences to the health of children.
\end{abstract}

Key words: Sepsis; newborn; metabolism; infection.

\section{INTRODUÇÃO}

A Encefalopatia Hipóxico Isquêmica (EHI) neonatal é uma doença devastadora para o cérebro do recém-nascido; ocorre em aproximadamente seis por 1000 nascidos vivos a termo ${ }^{1,2}$ e surge como problema de saúde pública de difícil solução. ${ }^{3-5}$ É mais prevalente nos países em desenvolvimento, é decorrente do insulto em si ou se instala na fase de reoxigenação-reperfusão. ${ }^{6}$ Contribui significativamente para a mortalidade e morbidade neonatais, inclui sequelas no desenvolvimento neurológico para $25 \%$ a $60 \%$ dos sobreviventes. $^{7}$

Nas últimas duas décadas, as pesquisas experimentais trouxeram grande avanço nos conhecimentos fisiopatológicos, como a descoberta da morte neuronal tardia mediada por liberação de substâncias nocivas, radicais livres e agentes inflamatórios, levando à possibilidade de tratamento mais efetivo. ${ }^{1}$ Para a integridade neuronal, é necessária energia suficiente para a célula manter o equilíbrio iônico. $\mathrm{O} \mathrm{Ca}^{2+}$ representa importante papel na excitação da membrana celular do neurônio que é mantida através de transporte ativo primário, das bombas eletrogênicas de $\mathrm{Ca}^{2+}$ dependentes de ATP. ${ }^{8}$

A hipotermia tem sido estudada como um método com alto grau de neuroproteção na EHI. ${ }^{5,9}$ Assim, o objetivo é verificar a potencialidade terapêutica da hipotermia como tratamento da EHI em recém-nascidos.

\section{MÉTODO}

Trata-se de manuscrito na forma de síntese de dados. Foram consultadas bases de dados do Journal Citation Reports (JCR-ISI), Medical Literature Analysis and Retrieval System Online (Medline), Scientific Eletronic Library Online (Scielo) e Literatura LatinoAmericana e do Caribe em Ciências da Saúde (Lilacs).

A pesquisa abrangeu os anos de 1993 a 2008, utilizando-se os descritores: recém-nascido, hipotermia, paralisia cerebral, fisiopatologia e encefalopatia (esses descrito- 
res foram utilizados nos idiomas inglês, português e espanhol). Estes descritores (DECs) foram pesquisados na Biblioteca Virtual em Saúde (BVS) da Biblioteca Regional de Medicina (BIREME).

A seguir, os artigos foram classificados quanto ao seu tipo: revisão sistemática, revisão explanatória e artigos originais (experimentais). Quanto ao modelo do estudo, foram divididos em: caso-clínico, caso-controle, experimental, observacional e síntese-interpretativa.

\section{RESULTADOS}

A distribuição dos manuscritos é descrita na Tabela 1 e a síntese dos resultados na Tabela 2 .

Tabela 1: Publicações e eipos de artigos relatados sobre encefalopatia hipóxico-isquêmica, no período de 1993 a 2008.

\begin{tabular}{lcccc}
\hline Tipo de Artigo & Medline & Scielo & Lilacs & JCR-ISI \\
\hline Caso-Clínico & 0 & 1 & 0 & 0 \\
Caso-Controle & 1 & 1 & 0 & 2 \\
Experimental & 2 & 7 & 0 & 1 \\
Observacional & 0 & 0 & 0 & 1 \\
Síntese-Interpretativa & 0 & 0 & 1 & 0 \\
Revisão Sistemática & 0 & 0 & 0 & 1 \\
Revisão Explanatória & 2 & 4 & 5 & 1 \\
Total & 5 & 13 & 6 & 6 \\
\hline
\end{tabular}

Scielo: Scientific Eletronic Library Online

Medline: Medical Literature Analysis and Retrieval System Online

Lilacs: Literatura Latino-Americana e do Caribe em Ciências da Saúde

JCR-ISI: Journal Citation Reports

Tabela 2: Síntese dos manuscritos sobre fisiopatologia da encefalopatia hipóxico-isquêmica neonatal.

Neves LAT $^{1}$

Silveira RC, Procianoy RS ${ }^{2}$

Cerqueira NF, Yoshida WB ${ }^{3}$

Carlotti CG. et al. ${ }^{4}$

Martinelli S. et al. ${ }^{5}$
Estudos experimentais têm contribuído para o avanço nos conceitos da fisiopatologia da EHI.

RN a termo com EHI apresentaram níveis liquóricos de IL-6 e TNF- $\alpha$ mais elevados que aqueles que não desenvolveram a EHI.

O óxido nítrico é um mediador gasoso que atua na permeabilidade vascular.

A respiração mitocondrial permitiu avaliação efetiva e precoce do processo isquêmico focal no cérebro de rato.

O uso de sistema hipertermia-hipotermia para o estudo de variabilidade da temperatura cerebral mostrou-se eficaz. 
Shankaran S. et al. ${ }^{6}$

Schulzke S. M. et al. ${ }^{7}$

Hilbig A, Coutinho AMB

Prandini MN. et al. ${ }^{9}$

Duarte SG. et al. ${ }^{10}$

Rimpilainen $\mathrm{J}^{11}$

Korc I. et al. ${ }^{12}$

Johnston MV. et al. ${ }^{13}$

Gagliardi RJ ${ }^{14}$

Zhu C. et al. ${ }^{15}$

Nakano H. et al. ${ }^{16}$

Muniz LRF. et al. ${ }^{17}$

Silva OC. et al. ${ }^{18}$

Tardini DMS. et al. ${ }^{19}$

Rutherford MA. et al. ${ }^{20}$

Battin MR. et al. ${ }^{21}$

Gonzáles LH. et al. ${ }^{22}$

Prandini MS. et al. ${ }^{23}$
Redução da temperatura cerebral reduz danos cerebrais após a encefalopatia neonatal.

A hipotermia terapêutica tem um efeito benéfico em recém -nascidos de termo com moderada ou severa encefalopatia hipóxicoisquêmica.

O limite entre a vida e a morte celular está relacionado às modificações iônicas.

A hipotermia local atua como neuroproteção por atenuação da resposta inflamatória.

O comprometimento da função mitocondrial ocorre após $30 \mathrm{mi}-$ nutos de isquemia e após uma hora de isquemia e reperfusão prolongada, não foram observadas alterações.

A depleção na filtração leucocitária aumenta a proteção cerebral após prolongado período de parada circulatória hipotérmica.

Os radicais livres têm influência na EHI do recém-nascido.

Insultos neurológicos severos podem desencadear cascata bioquímica auto-sustentada gerando danos excitotóxicos.

Ocorre liberação excessiva de aminoácidos excitatórios, principalmente o glutamato, na isquemia cerebral.

A hipotermia é possivelmente efetiva para a neuroproteção. Age através dos caminhos de ativação das caspases.

O tempo de duração da isquemia foi um fator determinante na alteração da respiração mitocondrial.

Após os primeiros minutos de reperfusão ocorrem as maiores alterações metabólicas causando lesões.

A reperfusão pode agravar as lesões produzidas na fase isquêmica isolada.

Os modelos de isquemia e reperfusão não demonstraram alterações consistentes de marcadores de lesão cerebral.

A hipotermia induzida pelo resfriamento do corpo todo ou seletivo da cabeça, reduz a injúria cerebral em animais recém-nascidos.

A Hipotermia seletiva da cabeça, combinada com moderada hipotermia sistêmica, é um método para reduzir a temperatura cerebral em recém-nascidos de termo após asfixia perinatal.

Hipotermia de corpo inteiro é praticável clinicamente.

Hipotermia moderada regional proporciona proteção aos cérebros isquemiados de coelhos. cérebros isquemiados de coelhos 
Blackmon LR, Stark AR ${ }^{24}$ O uso da hipotermia protetora em RN ainda é uma dicotomia.

Hickey RW. et al. ${ }^{25}$ Hipotermia seguida de hipertermia facilita o desenvolvimento de febre que pode exacerbar o dano cerebral.

Shankaran S. et al. ${ }^{26}$

A hipotermia é protetora em modelos animais, no entanto, a segurança e efetividade em recém-nascidos com encefalopatia é incerta.

EHI=Encefalopatia Hipóxico-Isquêmica

ATP=Adenosina Trifosfato

RN=Recém-nascido

IL= Interleucina

TNF $=$ Fator de Necrose Tumoral

Figura 1: Etapas Cronológicas da Apoptose

\begin{tabular}{|c|c|c|}
\hline FASE PRÉ-MITOCONDRIAL & $\begin{array}{c}\text { FASE DE DANO } \\
\text { MITOCONDRIAL } \\
\text { EFETORA } \\
\text { Programação irreversível } \\
\text { de morte celular }\end{array}$ & FASE PÓS MITOCONDRIAL \\
\hline 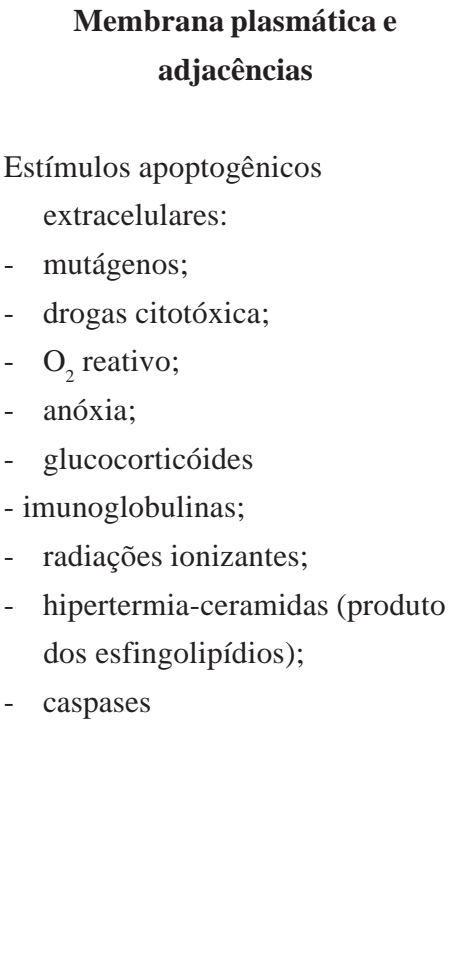 & $\begin{array}{l}\text { Membrana plasmática - } \\
\text { Matriz mitocondrial } \\
\text { - } \quad \text { incremento da } \\
\text { permeabilidade das } \\
\text { membranas; } \\
\text { - } \quad \text { saída de íons Ca }{ }^{2+} \text { da } \\
\text { matriz para o citosol } \\
\text { (ativador da caspase); } \\
\text { - } \quad \text { aumento da produção de } \\
\text { radicais livres; } \\
\text { - } \text { aumento do volume } \\
\text { mitocondrial (sweeling); } \\
\text { - } \text { ativação das caspases }\end{array}$ & $\begin{array}{l}\text { Todas as estruturas celulares } \\
\text { incluindo núcleo } \\
\text { - } \quad \text { saída dos fatores apoptogênicos } \\
\text { para o citosol; } \\
\text { - } \text { destruição das proteínas DNA, } \\
\text { RNA; } \\
\text { - } \text { ativação das caspases e } \\
\text { nucleases citosólicas; } \\
\text { - citocromo C+ fator Apaf-1, ATP } \\
\text { e caspase 9, formando } \\
\text { proteosoma; } \\
\text { - citocromo C ativa caspase } 3 \text { que } \\
\text { ativa endonuclease nuclear; } \\
\text { - } \text { proteínas intermembrana } \\
\text { incluem DNAase que degrada } \\
\text { dupla hélice: condensação da } \\
\text { cromatina; fragmentação de } \\
\text { DNA; degradação maciça de } \\
\text { proteínas; nucleólisis; citólisis. }\end{array}$ \\
\hline
\end{tabular}

Modificado de: Dubin M, Stoppani AOM ${ }^{27}$ 
Figura 2: Fisiopatologia de lesão encefálica hipóxico-isquêmica

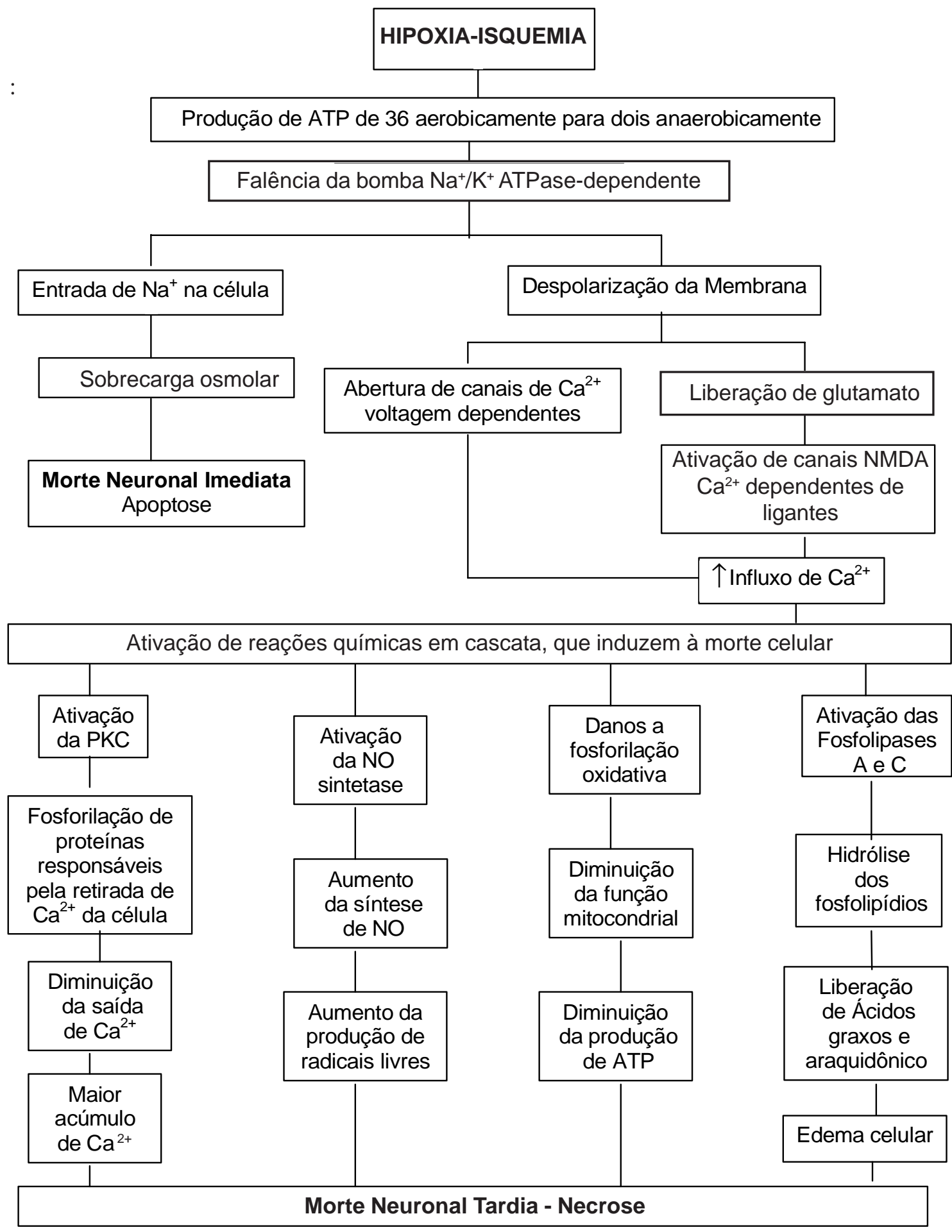

Araujo SA, Pacheco SS, Oliveira AG, Imaizumi C, Abreu LC, 2008. 


\section{DISCUSSÃO}

A Encefalopatia Hipóxico Isquêmica (EHI) neonatal é a complicação imediata à asfixia grave e pode causar graus variados de dano cerebra ${ }^{1}$, que associados a alterações metabólicas, levam às alterações fisiológicas, que se traduzem por manifestações clínicas secundárias ao comprometimento fisiológico ou estrutural. ${ }^{1,28}$

Não há mudanças histopatológicas num curto período de isquemia, porém a deterioração no estado energético com mudança metabólica ocorre rapidamente, podendo ser observada nos primeiros cinco minutos pós-isquemia; são mais pronunciadas na zona central do que na zona de penumbra e não progridem nos primeiros 30 minutos. ${ }^{10} \mathrm{O}$ dano cerebral após a isquemia inclui três fases: despolarização, cascata bioquímica e lesão de reperfusão. ${ }^{11}$

A redução da síntese de ATP prejudica o equilíbrio iônico através da membrana celular, invertendo as concentrações dos íons gerando edema cerebral ${ }^{1,12}$ e a excitotoxicidade é o processo responsável pelo dano da EHI. John Olney (1970) popularizou este termo, para explicar a fisiopatologia da isquemia cerebral, que se refere à morte celular mediada pelo excesso de estimulação excitatória extracelular nos receptores de aminoácidos. ${ }^{13,14}$

A cascata de eventos tem início com o neurotransmissor glutamato que atua como aminoácido excitatório no receptor NMDA, relacionado à abertura de canais de $\mathrm{Ca}^{2+}$ que, em altas concentrações, promove alterações indesejáveis como ativação das fosfolipases A e C, que leva a hidrólise dos fosfolipídios e gera agressão celular. ${ }^{14}$ Os ácidos graxos e o ácido araquidônico são liberados acarretando edema celular ${ }^{1}$ por influxo de $\mathrm{Na}^{+}$, $\mathrm{Cl}^{-}$e $\mathrm{H}_{2} \mathrm{O}$, que resulta em sobrecarga osmolar, ativa mensageiros secundários, fosforilação oxidativa e morte neuronal. ${ }^{1}$ Neste quadro de excitotoxicidade a produção de radicais livres ultrapassa a defesa antioxidante, gerando lesão na membrana plasmática e no citoplasma neuronal. ${ }^{14}$

Após esse evento osmótico, ocorrem na mitocôndria liberação do citocromo C que, associado a outros ativadores das caspases, modifica o transporte de elétrons, perda do potencial transmembrana, alteração do ciclo metabólico de óxido-redução, produção de radicais livres pela cadeia transportadora de elétrons e depleção de ATP, fatos estes que corroboram para a morte celular. ${ }^{29,30}$

Esta condição fisiopatológica gera uma retro-alimentação positiva, ou o chamado Ciclo de Hodkins Positivo, que gera despolarização da membrana, abertura de canais NMDA pelo glutamato e influxo $\mathrm{Ca}^{2+}$. Esse evento é mediado pela membrana plasmática, pelas $\mathrm{Ca}^{2+}$ ATPases do retículo endoplasmático e pelos mecanismos de transporte de $\mathrm{Ca}^{2+}$ ao nível da membrana plasmática, por transporte ativo, resultando em gasto de ATP. Enzimas celulares envolvidas em processos autodigestivos são ativadas pelo excesso de $\mathrm{Ca}^{2+}$ que estimulam uma seqüência de reações enzimáticas tóxicas ${ }^{5,13}$ que podem ser explicadas como: danos a fosforilação oxidativa, diminuem a função mitocondrial e a produção de energia; Ativação de fosfolipases que agem nos fosfolipídios contribui para a destruição da membrana neuronal; A ativação de proteases pelo $\mathrm{Ca}^{2+}$ com produção de radicais livres que agem na membrana fosfolipídica, quebram a membrana e destroem a cé- 
lula; Ativação da NOsintetase (NOS) aumenta os níveis de NO que produz radicais livres; Ativação da proteína quinase C (PKC), produz fosforilação de proteínas responsáveis pelos mecanismos de saída de $\mathrm{Ca}^{2+} .{ }^{14}$

As enzimas caspases, aumentadas pelo NO, ativadas pelo Citocromo C, que é liberado imediatamente após o episódio HI, iniciam e executam a morte celular programada, apoptose. ${ }^{1,15}$

Simultaneamente, há também a atuação da cascata inflamatória no processo de excitotoxicidade, que é a maior determinante da morte neuronal que segue a isquemia. ${ }^{9} \mathrm{Di}$ versas evidências experimentais indicam seu envolvimento na patogênese da lesão isquêmica cerebral. A isquemia do SNC aciona a reação inflamatória, que se caracteriza pelo influxo de leucócitos e monócitos, sugerindo o envolvimento de diversas citocinas, principalmente interleucina-6 (IL-6), fator de necrose tumoral$\alpha$ (TNF- $\alpha)$ e IL- $1 \beta .^{2}$

Os radicais livres, citados acima, agem desordenadamente $\mathrm{e}^{1,30} \mathrm{e}$ induzem necrose e apoptose ${ }^{29}$, sobretudo no RN pré-termo que nasce com uma proteção insuficiente contra os radicais livres de $\mathrm{O}_{2}{ }^{12}$

A necrose é um processo acidental, passivo, onde a morte celular se produz por um dano direto, irreversível, de todas as estruturas celulares, como na isquemia severa. ${ }^{16} \mathrm{O}$ processo pode terminar em uma neoformação tecidual, a cicatrização, com uma deformação da arquitetura do tecido. ${ }^{29}$

No mecanismo de apoptose a mitocôndria é o ponto principal. No quadro de EHI ela tem sua permeabilidade aumentada através da abertura de poros de transição, liberando múltiplas moléculas pro- apoptóticas, como o Citocromo $\mathrm{C}$ e as Caspases 2 e $3 .^{15}$

Além desses mecanismos de lesão, quando há recuperação do fornecimento de $\mathrm{O}_{2}$ e o restabelecimento da fosforilação oxidativa, ocorrem mais danos. A re-introdução do sangue oxigenado pode desencadear lesões teciduais intensas. Se a cadeia de transporte de elétrons mitocondriais fica comprometida, poderá desencadear alterações eletrolíticas e bioquímicas que aceleram a glicólise, causam produção exagerada de ATP com proporcional aumento da cadeia fosforilativa, fato este que aumenta a acidose lática, desencadeia a produção de radicais livres tóxicos que afetam a recuperação mitocondrial e atuam contra os efeitos benéficos da reperfusão inibindo a respiração mitocondrial o que torna impossível a recuperação ou agrava a lesão inicial. Esta é a situação conhecida como lesão de reperfusão. ${ }^{10,16,17}$

A manutenção de um fluxo sanguíneo reduzido na área isquêmica permite a ocorrência de disfunção celular sem morte eminente, isto permite uma recuperação celular dependendo do tempo e intensidade da isquemia. ${ }^{10,18}$ Este território cerebral, conhecido como zona de penumbra, é a meta das tentativas de recuperação nas isquemias definitivas e provavelmente o lugar onde as mudanças metabólicas podem causar a lesão de reperfusão. ${ }^{10}$

Na fase de reperfusão, os Ácidos Graxos Livres (AGL) acumulados no tecido cerebral, durante a isquemia, sofrem metabolização formando radicais livres que promovem a peroxidação lipídica, que se propaga na forma de uma reação em cadeia autocatalítica. ${ }^{19}$

A reperfusão parece não interferir com a função mitocondrial em tecidos cerebrais submetidos até 30 minutos de isquemia, po- 
rém períodos maiores fazem com que a retomada da função mitocondrial não seja completa e o consumo de $\mathrm{O}_{2}$, mantém-se abaixo do período pré-isquêmico. ${ }^{10,16}$

Nesta condição clínica o tratamento atual para as crianças com EHI é de suporte, com atendimento para as convulsões e estabilização dos parâmetros fisiológicos..$^{20,21}$

As características do dano $\mathrm{HI}$ indicam que existe um período intermediário, antes do dano secundário, em que é possível intervir interrompendo a cadeia de eventos que levam a destruição celular definitiva. Este período é chamado de janela terapêutica e evidências experimentais sugerem que não dura mais que seis horas. ${ }^{22}$

Baseando-se nesta janela, estudos focam maneiras de proteger o cérebro dos danos isquêmicos. Muitas drogas e diferentes procedimentos, como hipotermia, uso de manitol, removedores de radicais livres, antagonistas de receptores opiáceos, supressores de metabolismo, entre outros, são testados para minimizar as lesões. ${ }^{21}$

Outra estratégia protetora utilizada tem sido o resfriamento. Existem comunicações ${ }^{22}$ que datam de 1964 em estudos controlados que sugeriram uma melhor evolução neurológica em $\mathrm{RN}$ resfriados em banhos de água fria por 10 minutos após o nascimento. A hipotermia é um método de tratamento que promove efetividade em seu uso experimental e clínico. ${ }^{15,21}$

As bases fisiológicas para a neuro-proteção nas lesões isquêmicas encefálicas, através da hipotermia no tratamento da asfixia neonatal, é fato descrito na atualidade. ${ }^{24}$

Rosommoff, em 1956, foi o primeiro a reportar que a hipotermia profunda $\left(23^{\circ} \mathrm{C}\right)$ re- duzia o dano isquêmico após uma oclusão experimental da artéria cerebral média em cães. Igualmente, a hipotermia profunda ficou limitada devido ao grande número de efeitos indesejáveis quando da sua utilização, tais como, acidose, hipercoagulação sanguínea, demora na recuperação da anestesia, comprometimento hemodinâmico, arritmia miocárdica e hipotensão.

Por outro lado, a partir dos anos 90, diversos estudos têm corroborado com a hipótese do uso da hipotermia moderada $\left(31^{\circ} \mathrm{C}-\right.$ $33^{\circ} \mathrm{C}$ ), aquela mantida durante 80 a 100 minutos, de apresentar as mesmas propriedades protetoras, sem os efeitos deletérios da hipotermia profunda. ${ }^{9,23,24}$

Os riscos deste procedimento são proporcionais ao grau de resfriamento, quando o mesmo ocorre em temperaturas abaixo de $34^{\circ} \mathrm{C} .{ }^{25}$ Relatos de Blackmon et al. ${ }^{26}$ descrevem que Miller e Westin demonstraram um aumento na sobrevivência, sem paralisia cerebral ou retardo mental, em recém-nascidos que foram rapidamente resfriados de $23^{\circ} \mathrm{C}$ a $32^{\circ} \mathrm{C}$. Outrossim, um alto grau de proteção cerebral foi confirmado pelo abaixamento da temperatura a $32^{\circ} \mathrm{C}$ até duas horas após o dano isquêmico. ${ }^{9}$

Estudos experimentais em animais têm demonstrado que a moderada hipotermia, com uma redução de 3 a $4^{\circ} \mathrm{C}$ da temperatura corporal, imediatamente após a HI, preserva o ATP, reduz o edema citotóxico e melhora a função do tecido encefálico. ${ }^{20,26}$ Por outro lado, a redução da temperatura após seis horas do evento HI, e com instalação de crises convulsivas, não produz efeito neuroprotetor. ${ }^{18}$

A base biológica da neuroproteção com a hipotermia baseia-se no decréscimo no me- 
tabolismo energético, a diminuição da demanda de $\mathrm{O}_{2}$ pelo encéfalo, redução na densidade de aminoácidos excitatórios, redução da produção de radicais livres de $\mathrm{O}_{2}$ e redução da infiltração leucocitária nas áreas isquêmicas, diminuição da ativação microglial e da despolarização isquêmica. 9,11,15,22,23,26

Há diminuição do volume de edema cerebral, a liberação de Citocromo C e a sua ativação são menores após 72 horas de hipotermia, inferindo que a hipotermia pode atuar como inibidor da ativação das caspases no cérebro do RN, prevenindo a morte celular por apoptose. ${ }^{15}$

A hipotermia com resfriamento do corpo inteiro até $33,5{ }^{\circ} \mathrm{C}$, realizada nas primeiras seis horas após o nascimento e continuada por 72 horas reduz a morte e as sequelas severas e moderadas em RN de termo com encefalopatia. Em estudos experimentais em animais (ovelhas, ratos e porquinhos da índia), a hipotermia demonstrou ser benéfica quando implementada até cinco horas e 30 minutos após a isquemia cerebral. ${ }^{4,20,21,26}$

Por outro lado, a hipotermia seletiva da cabeça combinada com uma moderada hipotermia sistêmica de $34,4^{\circ} \mathrm{C}$ é um estável e bem tolerado método de reduzir a temperatura cerebral. $^{21}$

A hipotermia de corpo inteiro associada com a hipotermia seletiva da cabeça tem sido utilizada com o intuito de minimizar o risco de efeitos adversos sistêmicos. ${ }^{20}$ Shankaran et al. ${ }^{7}$ demonstram, em estudos com animais, que houve benefícios da hipotermia de corpo inteiro em reduzir a morte e as sequelas severas e moderadas no período neonatal.

A hipotermia de RN com EHI pode ser benéfica sobre a morte ou as sequelas em la- tentes avaliados aos 18 e 22 meses. Os efeitos adversos podem ser considerados pequenos se comparados aos benefícios potenciais ${ }^{7}$. Além disso, são proporcionais ao grau de resfriamento, com problemas de maior significância clínica ocorrendo em temperaturas bem abaixo de $34^{\circ} \mathrm{C}$. No entanto, experimentalmente, a neuroproteção ocorre em temperaturas de $34^{\circ} \mathrm{C}$ ou maiores..$^{5,21,25}$

Questões relevantes como temperatura, tempo de resfriamento e reaquecimento, local de resfriamento, ainda precisam ser respondidas ${ }^{20}$, bem como o uso concomitante de medicamentos removedores de radicais livres e antagonistas de glutamato. ${ }^{18}$

O sistema nervoso central (SNC) apresenta grande vulnerabilidade aos danos $\mathrm{HI}$. Nestas condições, diversos mecanismos de lesão são ativados e se comportam como uma cascata bioquímica num processo de excitotoxicidade, causando a morte de diversos neurônios.

Além disso, há lesão de reperfusão, causada por reações químicas que ocorrem em alguns neurônios no momento em que a circulação sanguínea e o fornecimento de $\mathrm{O}_{2}$ são regularizados, aumentando a lesão causada pelo dano inicial.

Por haver tantos mecanismos de lesão para o insulto HI, até a atualidade não existe um tratamento eficaz para impedir a instalação da EHI. Portanto, diversos estudos têm sido desenvolvidos com a finalidade de buscar este tratamento. Evidências indicam que a hipotermia em RN com EHI moderada ou severa, vem demonstrando eficácia neuroprotetora, pois reduz os riscos de morte e sequelas neurológicas sem efeitos adversos significativas. 
A consistência dos benefícios e suas bases científicas indicam que a hipotermia pode ser uma opção atrativa para a neuroproteção na EHI, porém para efetivá-la ainda são necessários mais estudos randomizados que comprovam este efeito benéfico.

Assim, a hipotermia é uma terapia promissora que precisa ser considerada e investigada o mais breve possível. Para confirmar a segurança e eficácia em testes com huma-

\section{REFERÊNCIAS}

1. Neves LAT. Encefalopatia hipóxicoisquêmica neonatal aspectos fisiopatológicos. Rev Med Minas Gerais 2005; 15: S43-S47.

2. Silveira RC, Procianoy RS. Níveis de interleucina-6 e fator de necrose tumoralalfa no líquor de recém-nascidos a termo com encefalopatia hipóxico-isquêmica. Jornal de Pediatria 2003; 79: 297-302.

3. Cerqueira NF, Yoshida WB. Óxido nítrico. Revisão. Acta Cirúrgica Brasileira 2002; 17: 417-423.

4. Carlotti CG, Colli BO, Kazuo JY. Avaliação da isquemia cerebral pela respiração mitocondrial. Arq Neuropsiquiatr 2001; 59: 365-371.

5. Shankaran, S. et al. Whole-Body hypothermia for Neonatal

Encephalopathy: Animal observations as a Basis for a Randomizer, Controled Pilot Study in Term Infants. Pediatrics 2002; 110: 377-385.

6. Martinelli, S. et al. Sofrimento Fetal: Fisiopatologia da Lesão Cerebral e Prevenção por Medicamentos. Rev. Ginec. \& Obstet 1998; 239-245.

7. Schulzke, S. M. et al. A systematic review of cooling for neuroprotection in neonates with hypoxic ischemic encephalopathy - are we there yet?. BMC Pediatrics 2007; 7:30-38. nos, é necessária a realização de estudos randomizados e controlados. ${ }^{20}$ Os recém-nascidos com encéfalopatia hipóxico-isquêmica desenvolvem quadros clínicos que os limitam nas atividades diárias, quer com lesões pontuais ou extensas do sistema nervoso.

A hipotermia é um recurso terapêutico a ser considerado na estratégia dea tratamento dos recém-nascidos acometidos com encefalopatia hipóxico-isquêmica.

8. Hilbig A, Coutinho AMB. Fisiopatologia da isquemia cerebral. Revista Pesquisa Médica 1993; 27: 45-48.

9. Prandini MN, Neves A, Lapa AJ, Stavale JN. Mild hypothermia reduces polymorphonuclear leukocytes infiltration in inducer brain inflamation. Arq Neuropsiuiatr 2005; 63: 779-784.

10. Duarte SG, Campos AD, Colli BO. Functional evaluation of temporary focal cerebral ischemia. Arq Neuropsiquiatr 2003; 61: 751-756.

11. Rimpilainen $\mathrm{J}$ et al. Leukocyte filtration improves brain protection after a prolonged period of hypothermic circulatory arrest: a study in a chronic porcine model. The J Thoracic and Cardiovascular Surgery 2000; 120: 1131-1141.

12. Korc I, Bidegain M, Martell M. Radicales libres. Bioquímica y sistemas antioxidantes. Implicancia en la patologia neonatal. Rev. Méd Uruguay 1995; 11: 121-135.

13. Johnston MV, Trescher WH, Ishida A, Nakajima W. Neurobiology of hypoxicisquemic injury in the developing brain. Pediatric Research 2001; 49:735-741.

14. Gagliardi RJ. Neuroprotection, excitotoxicicity and NMDA antagonists. Arq Neuropsiquiatr 2000; 58: 583-588..

15. Zhu C, Wang X, Cheng X, Qiu L, Xu F, Simbruner G, Blomgren K. Post- 
ischemic hypotermia-induced tissue protection and diminished apoptosis after neonatal cerebral hypoxiaischemia. Brain Research 2004; 996: 6775.

16. Nakano H, Colli BO, Roselino JES. Análise da respiração mitocondrial em tecido cerebral de gato após isquemia e reperfusão. Acta Cirúrgica Brasileira 2002; 17: 34-40.

17. Muniz LRF, Faria MHG, Vasconcelos PRL. Avaliação metabólica das lesões de isquemia e reperfusão cerebrais após oclusão bilateral das artérias carótidas comuns: estudo experimental em ratos. Acta Cirúrgica Brasileira 2004; 19: 529534.

18. Silva OC, Centurion S, Pacheco EG, Brisotti JL, Oliveira AF, Sasso K. Aspectos básicos da lesão de isquemia e reperfusão e do pré-condicionamento isquêmico. Acta Cirúrgica Brasileira 2002; 17: 96-100.

19. Tardini DMS, Yoshida WB, Novelli ELB, Sequeira JL. Avaliação de dois modelos experimentais de isquemia e reperfusão cerebral em ratos com oclusão temporária carotídea associada ou não à oclusão vertebral. Acta Cirúrgica Brasileira 2003; 18: 502-508.

20. Rutherford, M. A. et al. Mild Hypotermia and the Distribution of Cerebral Lesions in Neonates With Hypoxic-Ischemic Encephalopathy. Pediatrics 2005; 116:1001-1006.

21. Battin, M. R. et al. Treatment of Therm Infants With Head Cooling and Mild Systemic Hypotermia $\left(35.0^{\circ} \mathrm{C}\right.$ and $34.5^{\circ} \mathrm{C}$ ) After Perinatal Asphyxia. Pediatrics 2003; 111: 244-251.
22. Gonzáles LH, Toso MP, Kattan JS, Mesa TL, Pérez E. Tratamiente de la asfixia perinatal con hipotermia corporal total (Caso Clínico). Rev. Chil Pediatr 2005; 76: 275-280.

23. Prandini MS, Lacann SN, Valente PR, Stavale JN. Regional mild hipotermia in the protection of the ischemic brain. Acta Cirúrgica Brasileira 2002; 17: 232235.

24. Blackmon LR, Stark AR. Hypothermia: A neuroprotective therapy for neonatal hipoxic-ischemic encephalopathy. Pediatrics 2006; 117: 942-948.

25. Hickey, R. W. et al. Hypothermia and Hyperthermia in children After Resuscitation From Cardiac Arrest. Pediatrics 2000; 106: 118-122.

26. Shankaran S et al. Whole-body hypothermia for neonates with hypoxicischemic encephalopathy. N Engl J Med 2005; 353: 1574-1584.

27. Dubin M, Stoppani AOM. Muerte celular programada y apoptosis. Funcion de las mitocôndrias. Medicina (Buenos Aires) 2000; 60: 375-386.

28. Rotta NT. Paralisia Cerebral: novas perspectivas terapêuticas. Jornal de Pediatria 2002; 78: S48-S54.

29. Roseto A, Brenner C. Apoptosis o la muerte cellular programada. Arch Argent Pediatr 1999; 97: 253-275.

30. Kowaltowski AJ. Alternative mitochondrial functions in cell physiopathology: beyond ATP production. Braz J Med Biol Res 2000; 33: 241-250.

Recebido em: 16/08/2008 Modificado em: 28/09/2008 Aceito em: 05/11/2008 